\title{
XLVII. On a method of freezing at a distancé
}

\section{William Hyde Wollaston M.D. R.S. Sec.}

To cite this article: William Hyde Wollaston M.D. R.S. Sec. (1813) XLVII. On a method of freezing at a distancé , Philosophical Magazine Series 1, 42:186, 282-284, DOI: 10.1080/14786441308638331

To link to this article: http://dx.doi.org/10.1080/14786441308638331

$$
\text { 册 Published online: } 27 \text { Jul } 2009 .
$$

Submit your article to this journal $\pi$

\section{Article views: 2}


astonishing that a cellule surrounded with wood should extend, notwithstanding the obstacle thus presented to it. Every organized body is developed, and increases by a very powerful force, and the plant in developing itself breaks a very strong thread tied firmly round it.

Every cellule is a separate organ, destined to preserve and prepare the sap, to furnish it to other parts. The superfuity penetrates into the mealus intercellulares, and resembles anmal fat a litlle. The green matter which colours the plant is always in the cellules. It resists the action of water, but it is dissolved in alcohol: this solution is not precipitated by water like that of the resins. All the colouring matter of the leaves, the flowers, and the fruits, is contained in the cellules, as well as the acid, sweet, astringent or saline juices, \&c. Finally, we therein find the starch, which forms small grains, aud the mucilage, which sometimes forms small crains, sometimes small crystals, and occasionally it is fuid. Chemical analysis has discovered to me some very remarkable varieties between the mucilages of plants, which I shall mention in another place.

[To be continued.]

XLVII. On a Method of Freezing at a Distance. By William Hyde Wollaston, M.D. Sec.R.S.*

Trat a fluid, from which a portion is evaporated, becomes colder in consequence of the heat absorbed by that part which assumes the gaseous state; that fluids rise in the state of vapour at a lower temperature when the pressure of the atmosphere is removed, and consequently may be cooled to a lower degree by evaporation in vacuo than in the open air, are facts too well known to need confirmation before the Members of this Society by any new experiments.

Nevertheless, a new mode of applying the most established principles may deserve to be recorded, if it assist the illustration of them, and be instructive from the novelty of the view in which it exhibits a certain class of phænomena; although no immediate use be at present proposed, to which it can be applied with advantage.

If an attempt were made to freeze water by evaporation, without other means than the vacuum of an air-pump, the pump must be of the best construction; and though the

* From the Philosophical Transactions for 1813, part i. 
quantity of water be small, the receiver must be of large dinensions; otherwise its capacity would set too confined a limit to the quantity of vapour that will rise, and consequently to the degree of cold produced.

Supposing the commonly received estimates to be correct, as to the quantities of heat, that become latent in the conversion of ice into water, and of water into steam, being $140^{\circ}$ and $960^{\circ}$ respectively, we should find the following statement to be not far from the truth.

If 32 grains of water were taken at the temperature of $62^{\circ}$, and if one grain of this were converted into vapour by aissorbing $960^{3}$, then the whole quantity would lose $\frac{560^{\circ}}{32}=30^{\circ}$, and thus be reduced to the temperature of $32^{\circ}$.

If from the 31 grains, which still remain in the state of water, four grains more were converted into vapour by absorbing $960^{\circ}$; then the remaining 27 grains must have lost st of $960^{\circ}=142^{\circ}$, which is rather more than sufficient to convert the whole into ice. In an experiment conducted upon a small scale, the proportional quantity evaporated did not much differ from this esimate.

If it be also true, that water in assuming the gaseous state, even at a low temperature, expands to 1800 times its former bulk; then, in attempting to freeze the small quantity of water above mentioned, it would be requisite to have a dry vacuum with the capacity of $5 \times 1800$, or equal to that of 9000 grains of water.

As a means of avoiding the necessity of so large a vacuum, Mr. Leslie had recourse to the ingenious expedient. of employing an extensive surface of sulphuric acid, for the purpose of absorbing the vapour generated in the course of the experiment, and by that nieans contrived to freeze much larger quantitics of water than could otherwise have been done, and by a far less laborious process.

But even in this method the labour is not inconsiderable, and the apparatus, though adnurably adapred to the purpose for which it is designed, is large and cosily. I have therefore thought the little instrument I am about to describe may possess some interest, as affording a readier and more simple mode of exhibiting so amusing and instructive an experiment.

Let a glass tube be taken, having its internal diameter about $\frac{1}{8}$ of an inch, with a ball at each extremity of about one inch diameter; Plate IV. and let the tube be bent to a right angle at the distance of half an inch from each 
ball. One of these balls should contain a little* water, and the remaining cavity should be as perfect a vacuum as can readily be obrained. The mode of effecting this is well known to those who are accustomed to blow glass. One of the bails is made to terminate in a capillary tube; and when water admitted into the other has been boiled over a lamp for a considerable time, till all the air is expelled, the, capillary extremity, through which the steam is still issuing with violence, is held in the flame of the lamp till the force of the vapour is so far reduced, that the heat of the Hame has power to seal it hermetically.

When an instrument of this description bas been successfully exhausted, if the ball that is empty be immersed in a freezing mixture of salt and snow, the water in the other ball, though at the distance of two or three feet, will be frozen solid in the course of a very few minutes. The vapour contained in the empty ball is condensed by the common operation of cold, and the vacuum produced by this condensation gives opportunity for a fresh quantity to arise from the opposite ball, with proportional reduction of its temperature.

According to a theory that does not admit of positive cold, we should represent the heat of the warmer ball to be the agent in this experiment, generating steam as long as there remains any excess of heat to be conveyed. But if we would express the cause of its abstraction, we must say that the cold mixture is the agent, and may observe, in this instance, that its power of freezing is transferred to a distance, by what may be called the negative operation of steam.

The instrument, by which this is effected, may aptly be called a Cryophorus, which correctly expresses its office of trost-bearer.

XLVIII. Climate and Diversions in the Northern Parts of British India. Extracted from a Letter from an Oficer in the Army t.

"WE [one of His Majesty's regiments of infantry] arrived at Meerut in the middle of November. You can have no conception how cold the weather is at this place. This is the cold season; and I can assure you it is piercingly so.

- If the ball be more than half full, it will be liable to burst by the expansion of water in freezing.

+ Communicated by Dr. W. Thanison, Kansiagion. 